\title{
POSSIBILIDADE DE LEITURA CRÍTICA A PARTIR DO CONTO "THE LAST POOR MAN", DE MOACYR SCLIAR, MEDIADA PELAS TIC
}

\author{
Marli Teresinha da Silva* \\ Ernani Mügge** \\ Débora Nice Ferrari Barbosa ${ }^{* * *}$
}

RESUMO: O objetivo deste artigo é apresentar uma proposta de leitura crítica do conto "The last poor man”, de Moacyr Scliar, aplicada em aulas de Língua Inglesa do ensino médio. O roteiro de atividades está ancorado na metodologia de análise textual proposta por Juracy Assmann Saraiva (2001/2006), que tem por base a Estética da Recepção, e prevê a utilização das tecnologias da informação e da comunicação (TIC) e o exercício da interdisciplinaridade. Ao propor a leitura e análise de textos ficcionais brasileiros, traduzidos para o inglês, nas aulas, defende-se a ideia de que eles podem contribuir ao processo de ensino e aprendizagem na medida em que permitem, ao aluno, refletir sobre a realidade que o circunda e sobre si mesmo, atendendo, assim, às orientações explicitadas pelos documentos que orientam a educação do país.

PALAVRAS-CHAVE: Leitura; Língua Inglesa; Literatura Brasileira: “The last poor man”; TIC.

* Mestranda em Letras pela Universidade Feevale.

** Doutor em Letras (UFRGS), com estágio pós-doutoral (PNPD/CAPES) no Programa de Pós-Graduação em Processos e Manifestações Culturais, da Universidade Feevale, onde atua como professor e pesquisador. É autor de várias publicações voltadas para a prática docente no âmbito da leitura e da literatura e de obras ficcionais.

*** Doutora em Ciência da Computação pela Universidade Federal do Rio Grande do Sul (UFRGS) e Bacharel em Análise de Sistemas pela Universidade Católica de Pelotas (UCPel). Professora e pesquisadora do Programa de Pós-graduação em Diversidade Cultural e Inclusão Social, do Mestrado Profissional em Letras e dos cursos de Sistemas de Informação e Ciência da Computação da Universidade Feevale. 


\section{Considerações iniciais}

Ao que tange ao ensino de língua inglesa no âmbito do ensino médio, a leitura centra-se em textos de autores estrangeiros, cujo contexto de narração privilegia os países dos falantes da língua-alvo. Esta constatação pode ser comprovada mediante análise de livros didáticos oferecidos pelo MEC para as escolas públicas ou de livros didáticos importados, adotados, por vezes, pelas escolas privadas. Entretanto, entende-se que textos literários de autores brasileiros traduzidos também podem contribuir para o processo de ensino-aprendizagem em segunda língua, uma vez que levam o aluno a refletir sobre a realidade que o circunda e sobre si mesmo. Com efeito, a argumentação oral e escrita é enriquecida, pois torna-se mais provocativa, à medida que o contexto da narração se aproxima do contexto do aluno, podendo servir de base para pesquisa e arguição acerca de como os fatos narrados se desenvolveriam caso fossem vivenciados num contexto estrangeiro.

Desse modo, considera-se que as habilidades e as competências em língua inglesa a serem desenvolvidas pelo aluno de ensino médio devam ocorrer, também, a partir do contexto do aluno. Essa ideia vem ao encontro do que orienta o Programa Nacional do Livro Didático: Língua Estrangeira Moderna (PNLD, 2015), que defende que o livro didático deve oferecer textos (escritos e orais) sobre temas apropriados aos interesses do aluno, assim como textos que possibilitem maior reflexão sobre o contexto social e regional no qual a escola está inserida. Embora a prática de leitura aqui proposta não tenha a finalidade de desvalorizar o conteúdo do livro didático, é importante destacar que ela adere ao que está na legislação, tanto em relação àquela que regula o livro didático quanto à educação, como PCNs-EM/2000 e LDB/96.

Para exemplificar o posicionamento defendido, apresenta-se o trabalho realizado com o conto “The last poor man”, de Moacyr Scliar, que, além de valorizar 
a cultura nacional, articula-a com a estrangeira, na medida em que o texto traduzido permite a exploração de aspectos culturais como o léxico, a semântica, a fonética, valores sociais, a política, a economia, etc, que podem ser comparados entre uma cultura e outra.

Com a finalidade de tornar as atividades que constituem o roteiro de leitura mais interativas e colaborativas, optou-se pela utilização das tecnologias da informação e da comunicação (TIC) como suporte. As TIC, além de facilitar a colaboração entre o professor de língua inglesa, os alunos e os pais/responsáveis, permitem a colaboração de professores de outras disciplinas, como história e filosofia, valorizando a interdisciplinaridade.

A metodologia utilizada para a elaboração das atividades de análise textual prevê três etapas de leitura: compreensão, interpretação e aplicação. Elaborada por Saraiva (2001/2006) e ancorada na Estética da Recepção, essa metodologia promove um processo de leitura que instiga o aluno a alcançar o sentido do texto, sem deixar de lado o conhecimento prévio do educando. Ao seguir esse método, o aluno dá início a um processo de aprendizagem significativa, ao passo que relaciona o conteúdo da aula com a realidade, passando a refletir sobre aspectos do passado e do presente, relacionando-os e formulando suas próprias inferências. Sob esse ângulo, entende-se que a leitura age sobre o leitor, alterando a sua visão do mundo e, consequentemente, suas ações.

Como visto, o artigo procura mostrar que a tríplice aliança - literatura brasileira, língua inglesa e tecnologias - pode contribuir para a formação de alunos críticos. 


\section{Legislação para o ensino de língua inglesa no Brasil}

No âmbito do ensino médio, o ensino de língua estrangeira no Brasil é regulado pelos PCNs-EM/2000 e pela LDB/96, da mesma forma que o livro didático é regulado pelo PNLD/2015. Uma incursão nesses documentos legais mostra que o ensino de línguas estrangeiras modernas deve contribuir para a formação de cidadãos com autonomia intelectual, sendo dever da escola oferecer aulas de língua estrangeira que proporcionem uma aprendizagem significativa (PCNs-EM/2000).

Para tanto, os PCNs-EM (2000, p. 28-29) sugerem as habilidades e competências a serem desenvolvidas, entre elas, saber distinguir entre as variantes linguísticas; compreender de que forma determinada expressão pode ser interpretada em razão de aspectos sociais e/ou culturais; compreender em que medida os enunciados refletem a forma de ser, pensar, agir e sentir de quem os produz; utilizar os mecanismos de coerência e coesão na produção em língua estrangeira (oral e/ou escrita). [...]; utilizar estratégias verbais e não verbais para compensar falhas na comunicação [...].

Sob essa perspectiva, entende-se que a aprendizagem significativa deve abranger o contexto dos interlocutores, sejam eles professor-aluno, aluno-aluno, aluno-falante de língua estrangeira. Dessa forma, fica evidente a importância de uma abordagem cultural nas aulas de segunda língua. Acerca disso, investigou-se se a legislação orientava para o uso da literatura como meio de abordar a cultura no ensino de língua estrangeira. A resposta foi encontrada no PNLD (2015, p. 1215), que sugere que o professor se certifique se o livro didático contempla variedade de gêneros do discurso, concretizados por meio de linguagem verbal, não verbal ou verbo-visual, caracterizadora de diferentes formas de expressão na língua estrangeira e na língua nacional; discute relações de intertextualidade a partir de 
produções expressas tanto em língua estrangeira como em língua nacional; promove atividades que levem a novas formas de integração entre língua estrangeira e língua portuguesa e entre ambas e as demais áreas de conhecimento; oferece oportunidade de acesso a manifestações estéticas das diferentes comunidades que se identificam com a cultura estrangeira e com a nacional, com o propósito de desenvolver a fruição de produções artísticas.

Como visto, a legislação ancora o uso de material didático que tenha o texto como base e que tenha uma abordagem intercultural e interdisciplinar, destacando a importância de se respeitar o conhecimento prévio do aluno bem como o contexto em que ele está inserido. De modo semelhante, o documento indica que o professor escolha um livro didático que articule "os conteúdos de língua estrangeira com a área de linguagens, códigos e suas tecnologias, estabelecendo conexões também com as demais áreas e com a realidade" (PNLD, 2015, p.21). Emenda-se, a isso, o fato de a LDB/96 integrar as tecnologias à área das linguagens, no seu art. $35 \mathrm{~A}$.

Ao considerar o disposto na legislação, considera-se que o material didático apresentado ao aluno deva avançar para além de questões gramaticais, articulando o uso da língua estrangeira nos mais variados contextos sociais, bem como esteja integrado às tecnologias.

\section{$\mathrm{Na}$ literatura brasileira, o contexto do aluno}

A prática de leitura crítica proposta, neste trabalho, toma a legislação como ponto de partida e, dentro disso, valoriza o contexto do aluno. Desse modo, temse a literatura brasileira como fonte para o fortalecimento da integração entre o aluno e a sociedade em que ele vive. Entende-se que essa integração é possível em 
razão de o texto ficcional, traduzido, levar o aluno a identificar-se com os traços culturais das personagens e do meio onde o texto é narrado.

Sobre a identificação do leitor com as personagens, as situações e os lugares que encontra no texto, Anatol Rosenfeld defende que

[...] a grande obra de arte literária (ficcional) é o lugar em que nos defrontamos com seres humanos de contornos definidos e definitivos, em ampla medida transparentes, vivendo situações exemplares de um modo exemplar (exemplar também no sentido negativo). (ROSENFELD apud CANDIDO et alii, 2011, p. 45)

A passagem defende que, quando o leitor se depara com as situações vividas pelas personagens, ele pode (ou não) se identificar com elas, desencadeando um processo avaliativo, isto é, passa a refletir sobre si e sobre a realidade que o circunda. Desse diálogo entre texto e leitor pode emergir uma mudança de comportamento e de visão de mundo, de modo que se possa atribuir à literatura uma função social.

Como visto, sob o ângulo da cultura, o envolvimento entre o leitor e o narrado pode gerar uma nova relação desse leitor com o mundo. Sob um prisma linguístico, por sua vez, o texto traduzido possibilita discussões semânticas e fonéticas, à medida que, por vezes, toma emprestado uma palavra ou uma expressão do texto fonte para preencher uma lacuna metalinguística. Os textos literários em português contêm expressões ou palavras que não têm tradução para o inglês, ou, quando isso é possível, a sonoridade e as significações das mesmas não funcionam na narrativa, como ocorre em “The last poor man”, de Moacyr Scliar, que servirá de objeto para a apresentação do modelo de análise textual neste artigo. Na narrativa, aparecem as palavras cruzados, cruzeiros, Dona (Dona Laura), Senhor (Senhor João), Cinelândia e favela: 
A museum in Chicago exhibited a slum in miniature; a great attraction. Thousands of people visited the exhibit and displayed disbelief: "Did people actually live there?" In Rio de Janeiro, a favela was preserved just as it had been; ingenious mannequins representing black women walked up and down the hill, carrying cans of water on their heads (JACKSON, 2006).

No excerto do texto, quando o dado espacial remete à cidade americana, Chicago, o tradutor usa slum, mas quando se situa no Rio de Janeiro, cidade brasileira, usa "favela".

Ainda em "The last poor man", aparecem as palavras "cruzeiros" e "cruzados", moedas brasileiras que circulavam entre 1970 e 1989, que não encontram, na língua estrangeira, um par. "Dona" e "Senhor" têm tradução para o inglês, todavia, são vocábulos que, em português, podem ser usados diante de nomes, mas na língua inglesa não: Lady e Mr. são utilizados apenas antes de sobrenomes. "Cinelândia”, a Times Square brasileira, menor em tamanho, luxo e luzes que esta, mas que, assim como a americana, concentra em seu entorno vários prédios importantes para a cultura nacional, como o Teatro Municipal e a Biblioteca Nacional, também não tem tradução para o inglês. A Floresta Amazônica não está na lista das palavras mantidas em português, no entanto, faz-se necessário destacar que sua referência em língua inglesa dá a sensação de que ela não é uma riqueza natural do Brasil, mas, sim, mundial; como se the Amazon fosse comum a todos. Emenda-se, a isso, o fato de não se ter encontrado o texto em português, para verificar se a escrita do nome da floresta em inglês foi uma opção do autor, com a intenção de mostrar o quanto a população brasileira, ou parte dela, dava mais valor àquilo que remete ao estrangeiro.

Todavia, com relação à sintaxe, cada língua tem seu sistema de encadeamento das palavras, ou seja, de ordenar os signos. Esse sistema, que é característico 
de cada língua, não é alterado na tradução. Se fosse, o tradutor estaria desfigurando a língua-alvo. Para esclarecer este posicionamento, expõem-se aqui dois exemplos de tradução, a tradução intralingual ${ }^{1}$ e a interlingual ${ }^{2}$. Na primeira, falantes da mesma língua usam paráfrases ou explicações para termos e expressões desconhecidas, como ocorre na leitura de textos complexos como o de Guimarães Rosa, ou quando se conta uma história para uma criança. Mas isso não significa que a estrutura sintática da língua é alterada, o que ocorre é uma substituição de palavras. $\mathrm{Na}$ tradução interlingual, o sistema de códigos de uma língua é recodificado para a outra língua, [...] "assim a tradução envolve duas mensagens equivalentes em dois códigos diferentes." (JAKOBSON, 2012, p. 43).

O leitor de um texto traduzido, desse modo, estabelece as relações sintagmáticas e paradigmáticas na língua em que lê, adquirindo conhecimento lexical, semântico e fonético na segunda língua. Além disso, a leitura de textos traduzidos de autores brasileiros não priva o leitor do aprendizado da cultura dos países de língua inglesa, haja vista que o professor deve mediar reflexões sobre o fazer do texto, assim como acerca da cultura inserida nele e, assim, levantar questionamentos e posicionamentos sobre as semelhanças e diferenças culturais entre o Brasil e os países da língua estrangeira em estudo.

No entanto, faz-se necessário destacar que a escolha do texto é de fundamental importância para que o professor possa alcançar o objetivo desejado. Os critérios utilizados para a escolha de "The last poor man" podem apontar para

\footnotetext{
${ }^{1}$ A tradução intralingual, ou reformulação, consiste na interpretação dos signos verbais por meio de outros signos da mesma língua. [...] tradução intralingual de uma palavra utiliza outra palavra, mais ou menos sinônima, ou recorre a um circunlóquio. (JAKOBSON, 2012, p. 43)

2 A tradução interlingual, ou tradução propriamente dita, consiste na interpretação dos signos verbais por meio de alguma outra língua. (JAKOBSON, 2012, p. 43)
} 
aspectos relevantes na seleção da narrativa. Em primeiro lugar, é preciso dizer que a opção pelo gênero conto se deu em razão da linguagem e da estrutura desse tipo de texto, que apresenta um número reduzido de signos, dando origem a um texto conciso, mas prenhe de sentido e intensidade. A brevidade e a intensidade desse gênero textual têm o poder de arrebatar o leitor desde as primeiras linhas.

Nesse ponto, destaca-se que, ao encarar um conto, o leitor é levado a uma emoção intensa, que se estende até o final da leitura. Esse "estado de excitação", de acordo com Edgar Allan Poe (apud GOTLIB, 1995, p. 32), só é sustentado mediante leitura corrida, única, em "uma só assentada". Todavia, também é preciso evidenciar que essa leitura de uma só vez permite ao leitor perceber o texto como um todo de sentido. Essa visão "global” aguça a percepção do leitor para aquilo que o texto fala "mesmo no silêncio das entrelinhas" (MARIA, Luiza de. [19-], p. 72). Assim, o tempo de leitura de um conto configura-se em um instante de emoção e percepção.

A concisão do conto também permite a leitura e a exploração do seu sentido em curto tempo, já que, em geral, as escolas oferecem de um a dois períodos de aula de inglês por semana. Outro ponto a destacar é a facilidade de acesso a esse tipo de texto, facilmente encontrado na internet.

Assim, pelas razões mencionadas, a proposta elege o gênero conto como veículo de aprendizagem significativa e alia-se às TIC para potencializar essa aprendizagem.

\section{Tecnologias da informação e comunicação - TIC}

Neste trabalho as TIC são compreendidas como quaisquer formas de transmissão de informações e correspondem a todas as tecnologias que interferem e mediam os processos informacionais e comunicativos dos seres a partir de recursos 
digitais. A escolha das TIC como suporte à prática pedagógica de leitura, sugerida aqui, se justifica pelo fato de elas proporcionarem formas interativas e colaborativas de aprendizagem, podendo, assim, incentivar o exercício da argumentação oral e escrita entre alunos de ensino médio. Sob esse aspecto, elas se configuram em ferramentas de mediação para a elaboração e a execução de atividades e têm a finalidade de potencializar a comunicação entre professor-aluno, aluno-aluno, e permitindo, também, a inserção dos pais ou responsáveis. Igualmente a utilização das TIC promove o protagonismo do discente, na medida em que ele precisará se apropriar de habilidades necessárias para pesquisar na rede; acessar os arquivos e executar as tarefas; realizar a leitura compreensiva e interpretativa dos contos; expressar suas reflexões, a partir da leitura; colaborar e receber a colaboração dos colegas; questionar; seguir prazos.

Da mesma forma, a prática pedagógica sugerida requer um caráter proativo por parte do professor, que deverá se integrar às tecnologias para poder operar as ferramentas digitais e valer-se dos recursos que essas ferramentas oferecem para a elaboração de atividades criativas.

Em vista das possibilidades que se vislumbram com o uso das TIC como ferramentas de mediação, considera-se que o Edmodo, o Padlet, o Google Drive, o ELO - Ensino de Línguas On-line, o Free Newspaper Template e o QR - Code otimizam o processo de ensino-aprendizagem, ou seja, estreitam as relações entre os atores envolvidos, viabilizando a elaboração e a realização de tarefas sem as limitações de espaço e de tempo próprias do modelo convencional, que prevê a utilização de quadro branco, papel impresso, lápis e papel.

\section{Percurso metodológico}


A proposta de leitura e análise do conto "The last poor man" teve como finalidade motivar aluno e professor a engajarem-se em um processo de leitura em que ambos fossem protagonistas da construção do sentido do texto. Nesse sentido, amparou-se na metodologia proposta por Juracy Assmann Saraiva (2001/2006) ${ }^{3}$, que tem por base a Estética da Recepção, e prevê a análise do texto literário em três etapas sucessivas. A primeira etapa, denominada "Atividade introdutória à recepção do texto", é desenvolvida - como o próprio título sugere - antes do contato do aluno com o texto, e tem como propósito familiarizá-lo com a temática com a qual irá se deparar durante a futura leitura, de modo a despertar sua curiosidade sobre ela. Esse warm-up (aquecimento) que antecede a leitura pode ser em forma de imagens, música, vídeo, desde que acompanhados de perguntas que funcionem como um caminho para uma leitura significativa. A segunda etapa, chamada "Leitura compreensiva e interpretativa do texto”, dá-se em dois níveis: em um primeiro, ocorre a "leitura compreensiva", em que o leitor tenta descobrir "o que o texto diz" e busca esclarecer "como o texto diz aquilo que diz". Nessa fase, dependendo da dificuldade do texto, mais de uma leitura será necessária até o aluno perceber quais são e como os elementos de composição do texto - estrutura das ações, caracterização das personagens, tempo, espaço, interlocução entre narrador e narratário, discurso direto, indireto, indireto-livre etc. - determinam seu sentido. No segundo nível, de "leitura interpretativa", ele procura alcançar "o sentido do texto". Para tanto, o aluno deve estabelecer uma relação entre o texto e o contexto. $\mathrm{O}$

\section{${ }^{3}$ A proposta pode ser encontrada nas seguintes obras:}

SARAIVA, Juracy Assmann (org.). Literatura e alfabetização: do plano do choro ao plano da ação. Porto Alegre: Artmed, 2001.

SARAIVA, Juracy Assmann; MÜGGE, Ernani. Literatura na escola: propostas para o ensino fundamental. Porto Alegre: Artmed, 2006. 
resultado dessa inter-relação é que o aluno amplia seu conhecimento sobre a temática do texto. Entretanto, para atingir o objetivo da segunda etapa de leitura, é preciso que o professor elabore atividades que fragmentem o texto e auxiliem o aluno a encontrar as respostas acerca da estética e do sentido da narrativa. A terceira etapa, "Transferência e aplicação da leitura”, dá conta da correlação do conhecimento construído por meio da leitura com o contexto extraliterário, de maneira a ampliar o conhecimento do aluno. Ao correlacionar o contexto de produção narrativa e o atual, o aluno relaciona passado e presente, construindo um novo sentido ao texto.

\section{“The last poor man": roteiro de leitura}

Publicado em 1968, no livro "Carnaval dos animais"4, o conto apresenta uma projeção de como seria a sociedade em 1990. A projeção, narrada em 14 capítulos, expõe um panorama social, cultural, político e científico vigente no ano em que se passa a história.

O panorama apresentado é de paz, saúde e prosperidade mundial. As cidades estão livres de bactérias, de doenças degenerativas, de artrópodes e de pobreza. Contudo, para a surpresa mundial, um homem com características opostas às da sociedade - sujo, doente e pobre - é encontrado na floresta amazônica.

A descoberta, realizada por um antropólogo americano, que quer levar o homem (João) para o estrangeiro e estudá-lo, gera um sentimento de nacionalismo na população.

${ }^{4} \mathrm{O}$ conto foi publicado na $1^{\mathrm{a}}$ edição, de 1968 , mas, a partir da $2^{\mathrm{a}}$ edição, em 1976, foi retirado do livro. 
A partir dessa comoção nacional, o governo brasileiro encarrega-se de João, cuja vida é vasculhada e aniquilada na cruz.

O seguinte trabalho foi desenvolvido no terceiro ano de ensino médio de uma escola privada de Novo Hamburgo:

Atividade prévia

Cadastro do usuário e de sua senha no:

- Edmodo;

- Gmail ou Google Drive;

- ELO - Ensino de Línguas On-line.

- Instalar o leitor de QR Code no celular.

Atividade de pré-leitura

$\mathrm{Na}$ atividade de pré-leitura, o aluno precisou executar duas tarefas. A primeira consistiu na elaboração de uma apresentação sobre eventos e ações que aconteceram em 1968. Para tanto, precisaram clicar no link disposto no Edmodo, que os levou para o Power Point ${ }^{5}$, que está dentro do Google Drive. Como o Power Point é colaborativo, o aluno pode criar e editar a apresentação juntamente com outros colegas.

\section{${ }^{5}$ Links de acesso:}

Fragments of 1968 A $-<$ https://docs.google.com/presentation/d/1DYKbUjH_DmF30etenRI174ANmaLLsPHGYHDbCOKLdQ/edit>. Fragments of $1968 \mathrm{~B}-\mathrm{https} / /$ docs.google.com/presentation/d/1LOBpb7ltSOKRi5hyO9c-QjkrLKCPuIRDvCVudX_g_XM/edit\#slide=id.p>. Fragments of $1968 \mathrm{C}-$ $<\underline{\text { https://docs.google.com/presentation/d/1RO28zH32 NfYli8OOFMeNJx aVIAGr565xmPLdoTUGk/edit }}$ $>$ 
Figura 1 - Atividade de pré-leitura

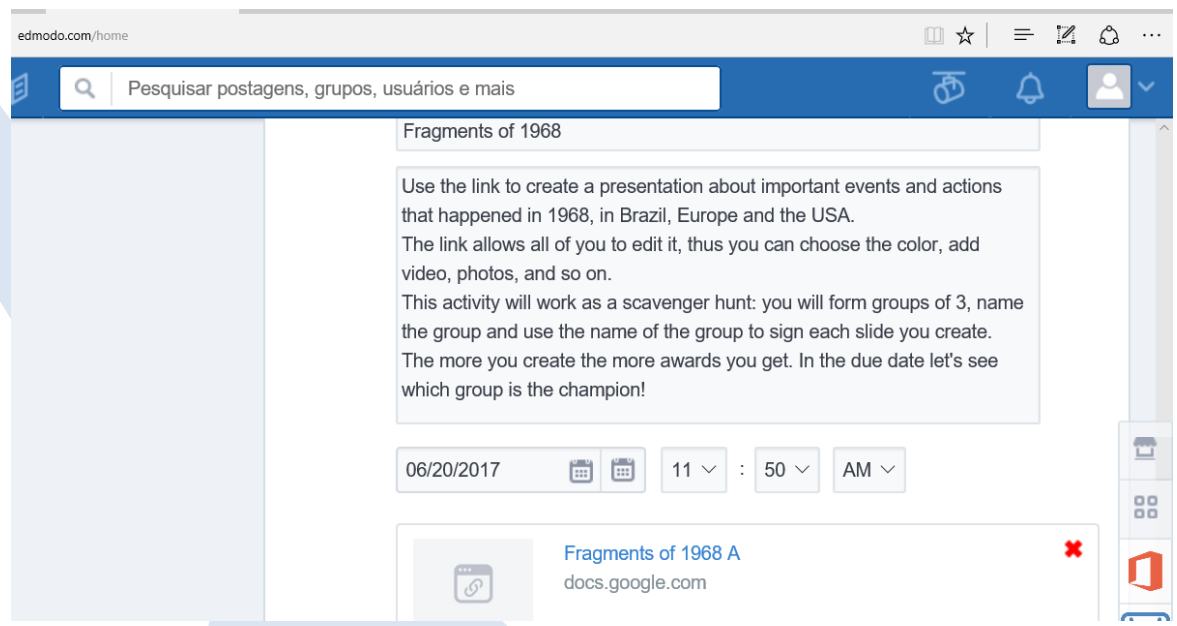

Fonte: a autora da proposta

A execução da tarefa envolveu pesquisa, criatividade, rapidez, cooperação e esmero. O professor acompanhou sua execução, interagiu com o aluno e deu seu feedback. Como a tarefa foi realizada em grupo, o professor pontuou e deu badges (distintivos) para os alunos do grupo que melhor se sobressaíram, iniciativa que havia sido combinada no início da atividade. O objetivo dessa tarefa foi contextualizar o ano de publicação do conto, para que o aluno tivesse informações relevantes que o ajudassem na compreensão do texto.

A segunda atividade foi um memory game ${ }^{6}$ com alguns vocábulos extraídos do conto e que remetem a um texto policial ou científico. A atividade teve como objetivo revisar os gêneros textuais.

${ }^{6}$ Link de acesso ao jogo da memória: http://www.elo.pro.br/cloud/aluno/atividade.php?id= 2026\&limpa_ score $=1$. 
Figura 2 - Memory game

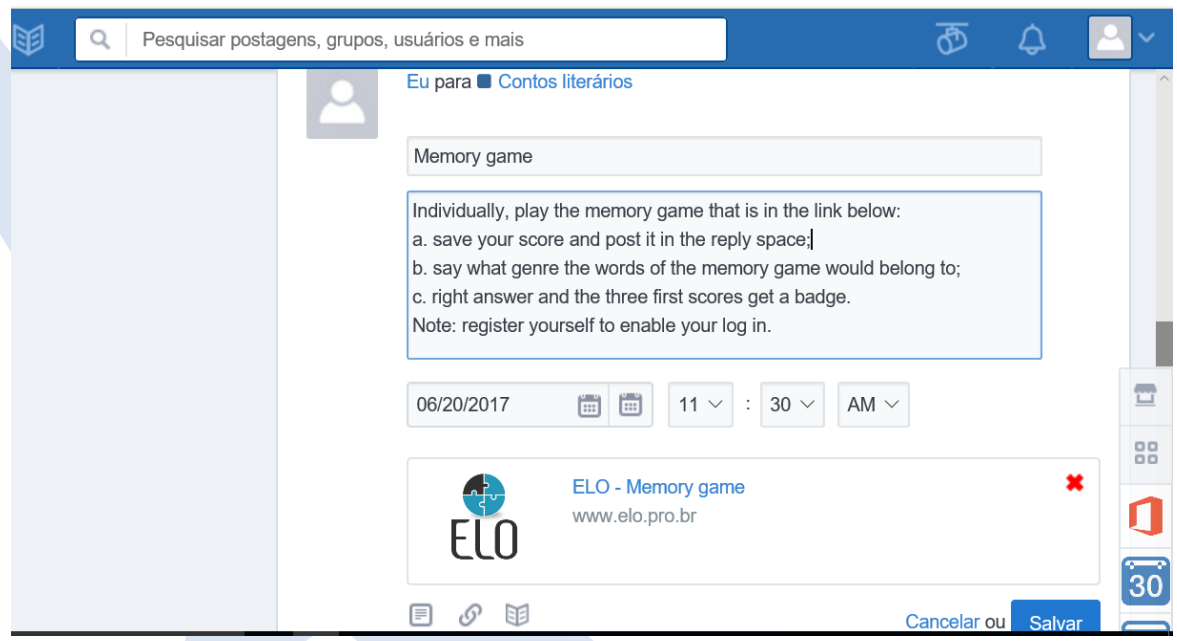

Fonte: a autora da proposta

A ferramenta utilizada para o jogo da memória foi o ELO, Ensino de Línguas On-line, que permite o acesso livre a professores, alunos e escolas. O resultado do jogo fica registrado, e o aluno pode copiar e colar o resultado no campo de resposta da atividade no Edmodo. Dessa forma, o professor pode dar uma distinção para os três melhores resultados.

Leitura compreensiva e interpretativa do texto

A leitura compreensiva e interpretativa do texto comportou três atividades: leitura do texto, Quiz digital e formulário de perguntas. Obs.: Para realizar a leitura do conto, o aluno deve ter no seu celular um leitor de QR Code - Quick Response Code-, que pode ser baixado gratuitamente. 
Figura 3 - Quick Response Code - QR Code (para acesso ao conto)

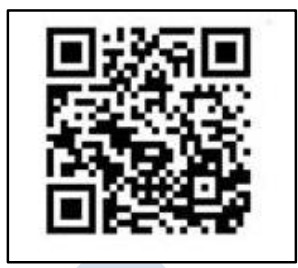

Fonte: a autora da proposta

O intuito desta tarefa foi instigar o aluno a descobrir o que o $Q R$ Code estava "guardando". Ao ler o código com o celular, o aluno descobriu o texto, que estava postado no Padlet, utilizado como uma ferramenta de acesso ao conto.

Após a leitura, iniciaram-se as atividades de compreensão. Para tanto, cada aluno precisou responder a um Quiz, cujas perguntas foram elaboradas para promover reflexões sobre o texto, ou seja, perceber o que o texto diz. O Quiz foi gerado no próprio Edmodo, cujo modelo pode ser visto nas Figuras 4 e 5.

Figura 4 - Quiz digital

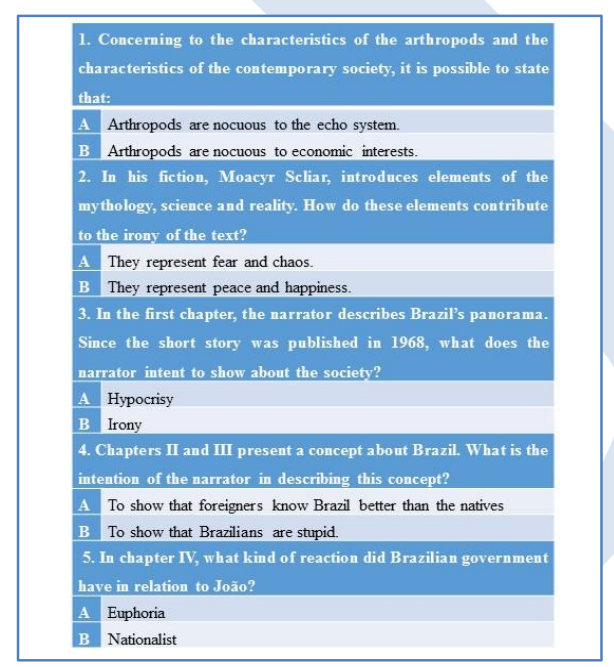

Fonte: a autora da proposta 
Figura 5 - Quiz digital

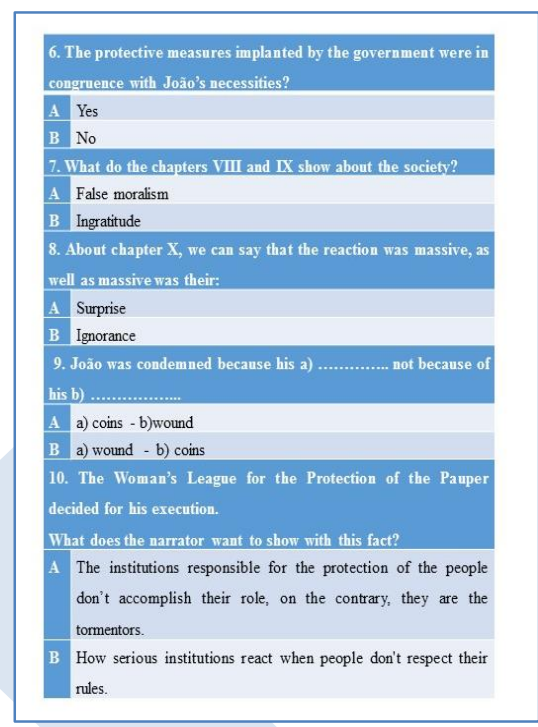

Fonte: a autora da proposta

A segunda tarefa dessa etapa do roteiro foi responder a perguntas inferenciais: seguiu-se com o modelo de pergunta do Quiz, mas as respostas não puderam ser optativas - o aluno foi motivado a elaborar um parágrafo argumentativo.

Answer the questions below:

a. Use the internet to search about the Time Square and "Cinelândia". Then, write three cultural things about them and give your opinion about what they have in commom.

b. "Cruzeiros" and "Cruzados" are Brazilian coins. Why do you think they were kept in Portuguese in the text?

c. "Dona" and "Senhor" are words that have their version in English, however, why do you think they are in Portuguese in the text? 
d. In the first chapter, the words "favela" and "slum" have he same meaning, but not the same signification in the text. How is this difference pointed?

i. ( ) Through the different contexts where they appear (a museum in Chicago and Rio de Janeiro).

ii. ( ) Through the language (English and Portuguese)

e. Based on the details of the execution imposed by the government, what can you say about the government?

f. Thinking about what happened to João, what is the objective of this short story?

g. How do the names and the division of the chapters contribute to the meaning of the short story?

O objetivo desta atividade visou promover reflexões sobre como o texto diz o que diz, além de ampliar o vocabulário do aluno. Esta foi uma atividade individual, realizada no Formulário de perguntas e respostas do Google drive $e^{7}$ Para executar a tarefa, o aluno precisou clicar no link disponível no Edmodo, responder às perguntas e clicar no ícone enviar. Dessa forma, as respostas foram diretamente para uma planilha do Google drive, onde o professor teve acesso e facilidade para a conferência.

${ }^{7}$ Link de acesso ao Formulário do Google drive: < https://docs.google.com/forms/d/1BDLL029GgefC00NqXK5owN04J2L1dY4RZqWhc5rkBo/edit>. 
Transferência e aplicação da leitura

A última etapa do roteiro exigiu que o aluno aplicasse o conhecimento adquirido durante a leitura compreensiva. Propôs-se a criação de um jornal que apresentasse projeções sociais, políticas, culturais e científicas para os próximos 22 anos. A proposta de atividade partiu do fato de que o conto, publicado em 1968, apresentou projeções para o ano de 1990, formando um intervalo de 22 anos entre a sua publicação e o ano em que se passa o evento. Nessa perspectiva, o aluno foi motivado a relacionar presente e passado, interligar ficção e realidade, ampliando, assim, seu conhecimento de mundo. Esta atividade foi realizada em grupo e demandou criatividade, uso de tecnologias, interatividade entre os componentes de cada equipe, uso da estrutura linguística do gênero textual produzido, conhecimento de mundo, pesquisa, releitura do conto, etc.

Para realizar a tarefa, o grupo acessou o General Newspaper Template, escolheu um modelo de jornal, escreveu suas projeções e salvou sua versão no arquivo. Em seguida, os textos foram projetados para a turma, o que gerou discussões reflexivas sobre suas as propostas.

\section{Considerações finais}

A elaboração de um roteiro de análise de texto literário, interligando língua inglesa, literatura e TIC, teve como finalidade a formação de leitores e o ensino de inglês para alunos no final do ensino médio. A proposta surge em vista da necessidade de haver atividades complementares ao livro didático, que ensinem inglês de forma interativa e colaborativa e que, como consequência, qualifiquem os alunos que queiram prestar o ENEM.

No entanto, era preciso que o roteiro se adequasse ao perfil dos alunos, que, ambientados ao mundo digital, não se interessam mais por aulas tradicionais. Dessa 
forma, ao buscar nas tecnologias da informação e comunicação ferramentas para a elaboração dos roteiros, encontrou-se o Edmodo, o QR Code, o Padlet, o ELO, o Google drive, o Free Template Newspaper. As TIC permitiram que o roteiro se adequasse ao que aduz a legislação e ao perfil do aluno. Sob o ângulo da legislação, o roteiro interliga as tecnologias e a aquisição de segunda língua, assim como se conecta a outras disciplinas. Desse modo, o roteiro avança para além dos conhecimentos metalinguísticos e amplia o conhecimento de mundo do discente. Atinente ao perfil do aluno, o roteiro respeita o conhecimento prévio e a forma com que o educando se comunica com o mundo.

Os resultados mostram que a professora e os alunos sentiram-se confortáveis em manusear a plataforma Edmodo, exprimindo comentários acerca da similaridade com o Facebook. Com relação à execução das atividades, os alunos declararam terem compreendido o proposto, na medida em que as ordens das tarefas foram claras e objetivas. Desse modo, ao que tange à utilização das tecnologias, a aderência dos alunos superou as expectativas, à medida que as TIC funcionaram como ferramentas de acesso, interação e colaboração escrita, mas também proporcionaram momentos espontâneos de oralidade na língua inglesa. Com relação ao desempenho de cada educando, as respostas registradas no Edmodo e a participação oral dos discentes mostraram que as atividades alcançaram sua finalidade, contribuindo para o aprendizado de segunda língua e para a formação do leitor. Além disso, as ferramentas oferecidas pela rede social Edmodo facilitaram o processo de avaliação.

Com efeito, ao ensinar uma segunda língua tendo por base o texto traduzido, a prática promoveu a cultura nacional, por abordar um conto que contextualiza a sociedade brasileira, oportunizando aos alunos discussões sobre aspectos históricos e culturais do país em que vivem. Porém, história e cultura de países de 
língua inglesa não ficaram de fora das discussões, tampouco o envolvimento com outras disciplinas, já que personagens e contexto pediram mais conhecimento sobre filosofia e biologia, comprovando que é possível elaborar atividades interculturais e interdisciplinares a partir de textos literários de autores brasileiros traduzidos, e que essas atividades podem ser mediadas pelas TIC.

\title{
CRITICAL READING POSSIBILITY FROM THE SHOR STORY “THE LAST POOR MAN", BY MOACYR SCLIAR, MEDIATED BY THE ICT
}

\begin{abstract}
The objective of this article is to present a proposal of critical reading for the short story "The last poor man", by Moacyr Scliar, which was applied in high school English classes. The activity guide is anchorated in the methodology of textual analysis proposed by Juracy Assmann Saraiva (2001/2006), which is based on the Aesthetic of Reception, and provides for the use of information and communication technologies (ICT) and the exercise of the interdisciplinarity. In proposing the reading and the analysis of Brazilian fictionals texts, translated into English, in the classes, we defend the idea that they can contribute to the teaching and learning process insofar they allow the student to reflect about the reality that surrounds him and about himself, attending, thus, the guidelines explicited in the documents that regulate the country's education.
\end{abstract}

KEYWORDS: Reading; English Language; Brazilian Literature: “The last poor man”; ICT.

\section{REFERÊNCIAS}

CANDIDO, Antonio e outros. A personagem de fição. São Paulo: Editora Perspectiva, 2011. GOTLIB, Nádia Batella. Teoria do conto. 7.ed. São Paulo: Editora Ática, 1995.

JACKSON, K. David. Oxford anthology of the Brazilian Short Story. Oxford University Press, 2006.

JAKOBSON, Roman. Linguística e comunicação. São Paulo: Editora Cultrix, 2012. Disponível em: <http://static.recantodasletras.com.br/arquivos/3827452.pdf?1345941387>. Acesso em: 11 jan. 2017.

LEI DE DIRETRIZES E BASES DA EDUCAÇÃO NACIONAL - LDB, 1996. Disponível em: <http://www.planalto.gov.br/ccivil_03/Leis/L9394.htm>. Acesso em: 02 mar. 2017.

MARIA, Luiza. O que é conto. São Paulo: Editora Círculo do Livro S/A. [19-] 
MINISTÉRIO DA EDUCAÇÃO - Secretaria da Educação Básica - MEC/SEB. 2015. Disponível em: <http://portal.mec.gov.br/secretaria-de-educacao-basica/apresentacao>. Acesso em: 26 jan. 2017.

MÜGGE, Ernani. Ensino Médio e Educação Literária: propostas de formação de leitor. 2011. 187f. Tese (Doutorado em Letras) - Programa de Pós-graduação em Letras, Instituto de Letras, Universidade Federal do Rio Grande do Sul, Porto Alegre, RS, 2011.

PARÂMETROS CURRICULARES NACIONAIS ENSINO MÉDIO, 2000. PCNsEM/2000. Disponível em: < http://portal.mec.gov.br/seb/arquivos/pdf/14_24.pdf>. Acesso em: 10 mar. 2016.

PROGRAMA NACIONAL DO LIVRO DIDÁTICO. PNLD - 2015. Disponível em: http://www.fnde.gov.br/programas/livro-didatico/guias-do-pnld/item/5940-guia-pnld2015. Acesso em: 03 jan. 2017.

SARAIVA, Juracy Assmann (org.). Literatura e alfabetização: do plano do choro ao plano da ação. Porto alegre: Artmed, 2001.

SARAIVA, Juracy A.; MÜGGE, Ernani. Literatura na escola: propostas para o ensino fundamental. Porto Alegre: Artmed, 2006.

SARAIVA, Juracy A.; BECKER, Celia Doris; MÜGGE, Ernani; LOPES, Gabriela Hoffmann; CAMARGO, Luís. Palavras, brinquedos e brincadeiras: cultura oral na escola. Porto Alegre: Artmed, 2011.

ZILBERMAN, Regina. Estética da recepção e história da literatura. São Paulo: Editora Ática S.A., 1989. 